\title{
Erratum to: Neuroprotective effects of constituents of the root bark of Dictamnus dasycarpus in mouse hippocampal cells
}

\author{
Gil-Saeng Jeong • Erisa Byun • Bin Li • \\ Dong-Sung Lee $\cdot$ Youn-Chul Kim $\cdot$ Ren-Bo An
}

Published online: 23 January 2014

(C) The Pharmaceutical Society of Korea 2014

Erratum to: Arch Pharm Res 33(8):1269-1275 (2010)

DOI 10.1007/s12272-010-0818-9

In the original version of the article titled "Neuroprotective effects of constituents of the root bark of Dictamnus dasycarpus in mouse hippocampal cells", published in
33(8):1269-1275, 2010 (DOI: 10.1007/s12272-010-08189), unfortunately an important change of the corresponding author was missing. The correct corresponding author's name with affiliation and the order of authors are given in this erratum.

The online version of the original article can be found under doi:10.1007/s12272-010-0818-9.

G.-S. Jeong

Zoonosis Research Center, Wonkwang University,

Iksan 570-749, Korea

E. Byun · B. Li · D.-S. Lee · Y.-C. Kim

College of Pharmacy, Wonkwang University, Iksan 570-749,

Korea

R.-B. An $(\bowtie)$

Key Laboratory of Natural Resources of Changbai Mountain \&

Functional Molecules (Yanbian University), Ministry of

Education, Yanji 133002, Jilin, China

e-mail: anrb@ybu.edu.cn 